\title{
Evaluation of Cancer Patient Satisfaction: A Transversal Study in Radiotherapy Department, Hassan II University Hospital, Fez, Morocco
}

\author{
Boujemaa EL Marnissi $\left(\mathbb{D},{ }^{1}\right.$ Fouad Abbass $\left(\mathbb{D},{ }^{1}\right.$ Hafida Charaka, ${ }^{1}$ Nawal Mouhoute, ${ }^{2}$ \\ Abdelaziz Tritha, ${ }^{3}$ Touria Bouhafa, ${ }^{4}$ and Khalid Hassouni ${ }^{4}$ \\ ${ }^{1}$ Research and Development Department, Hassan II University Hospital, Fez, Morocco \\ ${ }^{2}$ Communication Unit, Hassan II University Hospital, Fez, Morocco \\ ${ }^{3}$ Psychiatry Hospital, Hassan II University Hospital, Fez, Morocco \\ ${ }^{4}$ Radiotherapy Department, Hassan II University Hospital, Fez, Morocco
}

Correspondence should be addressed to Boujemaa EL Marnissi; boujemaa74@hotmail.com

Received 3 July 2019; Accepted 18 November 2019; Published 19 December 2019

Academic Editor: Carol J. Burns

Copyright (C) 2019 Boujemaa EL Marnissi et al. This is an open access article distributed under the Creative Commons Attribution License, which permits unrestricted use, distribution, and reproduction in any medium, provided the original work is properly cited.

\begin{abstract}
Patient satisfaction is an important quality outcome indicator of health care in the hospital setting. Patients are nowadays carepartners with caregivers. This relation is practically important for patients presenting chronic diseases, especially cancer. The aim of this study is to evaluate cancer patient satisfaction, treated at the department of Radiotherapy in Hassan II University Hospital, and to study the different components of this satisfaction. A prospective transversal study was conducted between December 2016 and January 2017. Data was collected by three inves-tigators based on structured interviews, a validated, anonymous and a standardized questionnaire. During this period, we have included 230 patients: 159 women (69.1\%), 71 men (30.9\%) and the sex ratio (women/ men) was 2.23 . Half of the investigated patients have never been schooled (52.61\%). The majority had urban origin (71.3\%) and $90 \%$ of patients declared being satisfied with the care at Radiotherapy department. $93.48 \%$ of cases recommended Radiotherapy department to other patients and $95.65 \%$ will want to continue their treatment at this department. Reception conditions were judged as favorable in $92.14 \%$. Satisfaction rates regarding the availability of medical and paramedics, health-care workers were $86.52 \%$ and $83.9 \%$ respectively. The quality of medical and paramedical care was judged as excellent or good in $78 \%$ cases. However, $44.34 \%$ of patients complained about the complexity of administrative formalities. $60.87 \%$ of cases judged that the waiting time was too long, whereas $31.4 \%$ of patients claimed that care-quality of their pain was insufficient or bad. The majority of patients declared being very satisfied or at least satisfied with different care services. For items that were judged as less satisfactory, some recommendations will be taken especially at the level of pain's and palliative care as well as the organization of patients' circuit inside the department. The satisfaction's variations can be attributed to personally patients factors as well as systemic ones at the level of the hospital. Assessing and understanding these factors are essential in developing appropriate measures to improve patient satisfaction.
\end{abstract}

\section{Introduction}

The degree of patient satisfaction reflects care-quality in every establishment's offer based on accessibility, continuity of medical and paramedical care, and care's financial repercussions related to the technical competence of doctors and nurses, interpersonal aspects, reception, orientation and communication between caregivers and patients [1]. Measuring this degree of satisfaction allows the adoption of a strategy about an optimal care of patients $[2,3]$; this is guaranteed through identifying care aspects to be improved in different health-care establishments. It allowed to describe the globally care from patients view and to identify problems as well as the suggestion of solutions [4].

The estimation of satisfaction is based on multiple means: patients' complaints, questionnaire and specific or general investigations conducted since the initiative of healthcare establishments [5]. Despite its presence in regulatory texts all 
over the world, patients' satisfaction is neglected by practitioners [6]. The literature review has demonstrated that, in most Occidental countries, the investigations of satisfaction's measurement are much more than in Africa. In Morocco, few studies have targeted the evaluation of patient satisfaction due to the absence of regulatory texts that impose the estimation of patient satisfaction as it done in other countries [7].

The study of satisfaction occupied a leading role for the patients with chronic diseases who have frequent contacts in health care institutions and because of the vulnerability related to their disease, in particular patients with cancer whose incidence is constantly increasing $[8,9]$.

The standardized incidence of cancer on the Moroccan population is 115.4 per 100,000 inhabitants and there are approximately 40000 new cases of cancer, which are detected each year in Morocco. The most common cancer, considering both sexes, was breast cancer, representing $20 \%$ of cases registered in 2012. Lung cancer is the second most common cancer, contributing $12.3 \%$ of all cases, followed by colorectal cancer with a proportion of $8 \%$, cervical cancer with $6.9 \%$, prostate with $6.3 \%$ and thyroid with a rate of $5.5 \%$. (Registre des cancers de la Région du Grand Casablanca (RCRGC) 2008-2012) [10].

The Hassan II University Hospital has its own cancer registry. According to this registry, 2877 new cases of cancer were recorded in 2017. The breast cancer was also the most common in both sexes, accounting for $22.9 \%$ of cases. Prostate cancer ranked second with $7.1 \%$, followed by cervical cancer with $7 \%$ and lung cancer with 6.3\%. (Registre Hospitalier des cancers du CHU Hassan II, Rapport, 2017) [11].

The percentage of new cases in Hassan II University Hospital is nearly $7 \%$ compared to national data. In addition, at Hassan II University Hospital, about $40 \%$ of cancers are treated in Radiotherapy department, whereas approximately $60 \%$ of cases are diagnosed in the metastatic or locally advanced stage. Recently, our hospital endeavors to promote palliative care as a core component of health systems (Rrgistre Hospitalier des cancers du CHU Hassan II, Rapport, 2017) [11].

The evaluation of cancer patients satisfaction has become an essential criteria element to improve the quality of medical and paramedical care and the pain treatment as well as the side-effects associated with medication. Cancer treatment can cause side effects which influence patients' therapeutic adhesion. This problem can be seen, in Radiotherapy department, where patients received daily cures during a long period. Our study was the first experience to measure the patients' level of satisfaction with the quality and care of the healthcare service at Radiotherapy department, in Hassan II University Hospital. This study allowed determining different component improving patients' care and treatment adhesion and to evaluate the satisfaction of cancer patients, cured at this department.

\section{Materials and Methods}

2.1. Type and Population Study. This is a prospective transversal study including a sample of cancer patients who were treated at Radiotherapy department in Hassan II University Hospital during a period between December 2016 and January 2017. We have included in this study all patients who have received Radiotherapy or Brachytherapy as well as other departments relevant to oncology. We have excluded mentally-retarded patients or the ones having a psychiatric affection, under-aged children. We have also omitted incomplete questionnaires.

2.2. Data Collection. A multidimensional questionnaire was presented to the patient or his companion at the end of treatment. This questionnaire was developed according to international standards and national data. It composed of two parts; the first one included patients' socio-demographic and medico-administrative data and the second part contained several items exploring satisfaction: the overall satisfaction, specific satisfaction related to patients' accessibility to hospital and Radiotherapy department, the conditions of reception and waiting, the therapeutic procedure, pain's and discomforts' management, information and communication, human aspect of medical and paramedical personnel, hotel conditions, expectations and proposals to improve care quality.

Data collection was conducted by three investigators, using a face-to-face questionnaire written in Arabic and validated with a pre-test. That questionnaire was presented to patients after treatment and the patient's consent was systematically requested after having explained to the participants the purpose of the study in which they were free to participate. In this study, anonymity and confidentiality were respected.

2.3. Statistical Analysis. The data were presented in Excel $^{\varpi}$ and then analyzed by the Epi Info ${ }^{\oplus} 7.2$ software. We proceeded to a descriptive analysis by establishing the means and standard deviations for the quantitative variables, the frequencies and percentages for the qualitative variables.

\section{Results}

3.1. Description of the Surveyed Population. A total of 230 patients were interviewed. Twenty-six patients refused to participate in the study, due to various reasons such as no availability or simply their reluctance to participate in the study. The average age of the patients interviewed was $54 \pm 13$ years with extremes ranging from 20 to 105 years. The surveyed population consisted of 71 men (30.9\%) and 159 women $(69.1 \%)$, (sex ratio of women $/$ men $=2.23$ ). More than half of the patients were illiterate $(52.61 \%)$ and the majority of patients (92.61\%) had health insurance. One hundred and eighty-seven patients $(81.30 \%)$ had a professional activity. The majority of patients were from urban (71.3\%). They were referred to Hassan II university hospital by another hospital structure (58.26\%) (Table 1).

3.2. Global Satisfaction. In our population, $90 \%$ of patients declared being very satisfied or satisfied with the offered care at the Radiotherapy department, $93.48 \%$ would rather recommend Radiotherapy department to their relatives who are cancer affected and $95.65 \%$ think they will regularly follow their traitment at the same department. However, only $64 \%$ judged that appointments at the radiotherapy department were satisfactory or very satisfactory (Table 2). 
TABLE 1: Sociodemographic characteristics of cancer patients (Hassan II CHU, Fez, 2017).

\begin{tabular}{|c|c|c|c|}
\hline Variable & & Number & $\%$ \\
\hline Age (year) & Average: $54 \pm 13$ & & \\
\hline \multirow{3}{*}{ Sex } & Male & 71 & 30.90 \\
\hline & Female & 159 & 69.10 \\
\hline & $\mathrm{Fez}$ & 105 & 45.65 \\
\hline \multirow[t]{2}{*}{ Provenance } & $\begin{array}{l}\text { Less than } 100 \mathrm{Km} \\
\text { from Fez }\end{array}$ & 53 & 23.04 \\
\hline & $\begin{array}{l}\text { More than } 100 \mathrm{Km} \\
\text { from Fez }\end{array}$ & 72 & 31.30 \\
\hline \multirow{2}{*}{ Residence } & Urban & 164 & 71.30 \\
\hline & Rural & 66 & 28.70 \\
\hline \multirow{5}{*}{ Educational level } & Illiterate & 121 & 52.61 \\
\hline & Quranic school & 10 & 4.35 \\
\hline & Primary & 44 & 19.13 \\
\hline & Secondary & 41 & 17.83 \\
\hline & High & 14 & 6.09 \\
\hline \multirow{3}{*}{ Family status } & Single & 42 & 18.26 \\
\hline & Married & 181 & 78.70 \\
\hline & Divorced & 7 & 3.04 \\
\hline \multirow{2}{*}{ Profession } & Yes & 43 & 18.70 \\
\hline & No & 187 & 81.30 \\
\hline \multirow{2}{*}{ Health insurance } & No & 17 & 7.40 \\
\hline & Yes & 213 & 92.61 \\
\hline \multirow{3}{*}{$\begin{array}{l}\text { Reference to Hassan } \\
\text { II CHU }\end{array}$} & Auto-referred & 34 & 14.78 \\
\hline & $\begin{array}{c}\text { Referred by a third } \\
\text { part }\end{array}$ & 62 & 27.0 \\
\hline & $\begin{array}{l}\text { Referred by a health- } \\
\text { care establishment }\end{array}$ & 134 & 58.26 \\
\hline
\end{tabular}

TABLE 2: Overall satisfaction of cancer patients (Hassan II CHU, Fez, 2017).

\begin{tabular}{lccc}
\hline & & Number & $\%$ \\
\hline How do you qualify the & Very satisfactory & 78 & 33.91 \\
offered services in this & Satisfactory & 129 & 56.09 \\
department? & Insufficient & 21 & 9.13 \\
& Very bad & 2 & 0.87 \\
Would you recommend & Indeed & 127 & 55.22 \\
this department to your & Probably yes & 88 & 38.26 \\
family? & Probably no & 11 & 4.78 \\
& Never ever & 4 & 1.74 \\
Do you intend to come & Yes & 220 & 95.65 \\
back to this department? & No & 10 & 4.35 \\
& Very satisfactory & 20 & 8.70 \\
How did you found & Satisfactory & 119 & 51.74 \\
appointments at this & Less satisfactory & 47 & 20.43 \\
department? & Unsatisfactory & 36 & 15.65 \\
\hline
\end{tabular}

\subsection{Assessment of the Specific Parameters of Satisfaction}

3.3.1. Reception Conditions and Comfort. The conditions of reception were judged very good. In fact, $83.04 \%$ of patients were very satisfied or satisfied with reception at the hospital
TABLE 3: Cancer patient satisfaction with reception conditions and comfort (Hassan II CHU, Fez, 2017).

\begin{tabular}{|c|c|c|c|}
\hline & & Number & $\%$ \\
\hline \multirow{4}{*}{$\begin{array}{l}\text { Reception at hospital's } \\
\text { entrance }\end{array}$} & Very satisfactory & 78 & 33.91 \\
\hline & Satisfactory & 113 & 49.13 \\
\hline & Insufficient & 29 & 12.61 \\
\hline & Very bad & 10 & 4.35 \\
\hline \multirow{4}{*}{$\begin{array}{l}\text { Reception by } \\
\text { radiotherapy } \\
\text { personnel }\end{array}$} & Very satisfactory & 113 & 49.13 \\
\hline & Satisfactory & 99 & 43.04 \\
\hline & Insufficient & 16 & 6.96 \\
\hline & Very bad & 2 & 0.87 \\
\hline \multirow{4}{*}{$\begin{array}{l}\text { Orientation inside the } \\
\text { hospital }\end{array}$} & Very satisfactory & 85 & 36.96 \\
\hline & Satisfactory & 68 & 29.57 \\
\hline & Insufficient & 47 & 20.43 \\
\hline & Very bad & 30 & 13.04 \\
\hline \multirow{4}{*}{$\begin{array}{l}\text { Administrative } \\
\text { formalities and } \\
\text { procedures }\end{array}$} & Very easy & 22 & 9.57 \\
\hline & Easy & 106 & 46.09 \\
\hline & Complicated & 72 & 31.30 \\
\hline & Very complicated & 30 & 13.04 \\
\hline \multirow{4}{*}{ Locales' cleanliness } & Very satisfactory & 99 & 43.04 \\
\hline & Satisfactory & 101 & 43.91 \\
\hline & Insufficient & 16 & 6.96 \\
\hline & Very bad & 14 & 6.09 \\
\hline \multirow{4}{*}{$\begin{array}{l}\text { Comfort of hospitali- } \\
\text { zation's room }\end{array}$} & Very satisfactory & 194 & 84.35 \\
\hline & Satisfactory & 19 & 8.26 \\
\hline & Insufficient & 5 & 2.17 \\
\hline & $\begin{array}{c}\text { Not satisfactory } \\
\text { at all }\end{array}$ & 12 & 5.22 \\
\hline \multirow{4}{*}{ Served meals } & Very good & 46 & 20 \\
\hline & Good & 71 & 30.87 \\
\hline & $\mathrm{Bad}$ & 93 & 40.43 \\
\hline & Very bad & 20 & 8.70 \\
\hline
\end{tabular}

entrance, and $92.14 \%$ were equally satisfied at the Radiotherapy department. The orientation was judged as satisfactory or very satisfactory by 153 patients $(66.54 \%)$, while $44.34 \%$ of patients claimed that procedures were complicated or very complicated. Waiting time at the Radiotherapy department was considered very long by 140 patients $(60.87 \%)$ and quite long by 42 patients (20.87\%), while others considered it reasonable (18.26\%). Waiting conditions were estimated to be very satisfactory or satisfactory in $67.25 \%$ cases. For hospitalized patients, $84.35 \%$ declared that they were very satisfied with rooms' comfort and $86.95 \%$ were very satisfied or satisfied with room's property. As far as the served meals, $49.13 \%$ of the patients described them as bad or very poor quality (Table 3).

3.3.2. Information, Communication, and Relation with Caregivers. In general, information and communication were judged as satisfactory in the majority of situations. In fact, $88.26 \%$ of patients obtained responses to their requests. The explanations given by medical staff were considered as clear, which are better demonstrated as follows: $75.65 \%$ related to their health problems, $79.13 \%$ concerning treatment, $81.74 \%$ for the exams to undergo and $68.26 \%$ about life style. In 
TABLE 4: Cancer patients' satisfaction with information, communication and relation with caregivers (Hassan II CHU, Fez, 2017).

\begin{tabular}{|c|c|c|c|}
\hline & & Number & $\%$ \\
\hline \multirow{4}{*}{ Have you ever had answers to the questions you addressed to doctors, nurses and physicians? } & Always & 153 & 66.52 \\
\hline & Often & 50 & 21.74 \\
\hline & Rarely & 25 & 10.87 \\
\hline & Never & 2 & 0.87 \\
\hline \multirow{4}{*}{ Has your doctor lucidly explained your health problem? } & Absolutely & 92 & 40 \\
\hline & Rather yes & 82 & 35.65 \\
\hline & Rather no & 32 & 13.91 \\
\hline & Never & 24 & 10.43 \\
\hline \multirow{4}{*}{ Has your doctor explained to you the way you should use medicines? } & Absolutely & 117 & 50.87 \\
\hline & Rather yes & 65 & 28.26 \\
\hline & Rather no & 16 & 6.96 \\
\hline & Never & 31 & 13.48 \\
\hline \multirow{4}{*}{ Has he/she explained to you the exams you should undergo? } & Absolutely & 127 & 55.22 \\
\hline & Rather yes & 61 & 26.52 \\
\hline & Rather no & 20 & 8.70 \\
\hline & Never & 22 & 9.56 \\
\hline \multirow{4}{*}{ Except the treatment, has your doctor explained to you hygienic measures of daily life? } & Absolutely & 107 & 46.52 \\
\hline & Rather yes & 50 & 21.74 \\
\hline & Rather no & 69 & 30 \\
\hline & Never & 4 & 1.74 \\
\hline \multirow{4}{*}{ In the care process, have health-care professionals identified themselves to you? } & Yes, all & 21 & 9.13 \\
\hline & Yes, the majority & 50 & 21.74 \\
\hline & Rarely & 56 & 24.35 \\
\hline & No, never & 102 & 44.35 \\
\hline
\end{tabular}

contrast, only $30.87 \%$ of professionals identified themselves to patients (Table 4).

3.3.3. Medical and Paramedical Care. The majority of interviewed cancer patients were very satisfied or satisfied with the availability of medical $(86.52 \%)$ and paramedical personnel (83.9\%). Medical and paramedical care quality were judged as excellent or good in $78 \%$ cases.

About half of patients (47\%) declared having suffered from pain associated with their pathology. Among them, 34.25\% declared having more intense pain, whereas $28.7 \%$ had less strong pain. Nearly $1 / 3$ of patients $(31.48 \%)$ declared having received a cure to their pain without any delay, whereas $49.1 \%$ and $19.42 \%$ affirmed that the delay was a long and very long respectively. $20.9 \%$ of patients declared having a complete benefit from pains medication whereas $82.8 \%, 2 \%$ declared that the pain was partially attenuated. Only 15 patients affirmed that their pain was not alleviated.

In general, $68.5 \%$ confirmed that the pain's cure was very satisfactory or satisfactory. However, $31.5 \%$ declared that medication was insufficient or bad. For those who suffered from parallel discomforts (nausea, vomiting bad postures, vertigo and fatigue), $60.76 \%$ was very satisfied or satisfied with the received care (Table 5 ).

3.3.4. Human Aspect. Regarding the behavior of radiotherapy's personnel, it was judged as excellent or good (90\% for doctors' behavior, $82.53 \%$ and $77.73 \%$ for nurses' comportment and physicians and technicians respectively). As for human respect, $83.91 \%$ declared being cured respectably. In contrast, $12.61 \%$ declared that their intimacy was not respected (Table 6).

\section{Discussion}

This satisfaction survey is the first one conducted on cancer patients treated at the Radiotherapy department, Hassan II University Hospital of Fez. Among patients interviewed, the response rate was $90 \%$. This reflects the willingness of our patients to participate in care's improvement. The results of this survey showed a very high rate of overall satisfaction (90\%) and a preliminary study on the satisfaction of cancer patients in the same institution affirmed similar results $(87.1 \%)$ [12]. This study was however destined to cancer patients treated in surgical departments in Hassan II University hospital.

Eventhough it is a difficult to adopt the results of foreign studies into the Moroccan context, the results of our study was better or similar to others moroccan studies [13-16] or countries sharing similar socio-economic levels [17-23].

The majority of items were rated very satisfactory or satisfactory by over $80 \%$ of patients. The principal items concerned reception and comfort, relationship with nursing staff, quality of medical and paramedical care, human aspect, information and communication. Similar or better results have been obtained in other European, Asian and Canadian studies [24-28]. 
TABLE 5: Cancer patient satisfaction with medical and paramedical care (Hassan II CHU, Fez, 2017).

\begin{tabular}{|c|c|c|c|}
\hline & & Number & $\%$ \\
\hline \multirow{4}{*}{ Availability of medical personnel } & Very satisfactory & 73 & 31.74 \\
\hline & Satisfactory & 126 & 54.78 \\
\hline & Less satisfactory & 24 & 10.43 \\
\hline & Unsatisfactory & 7 & 3.04 \\
\hline \multirow{4}{*}{ Medical care quality } & Excellent & 60 & 26.09 \\
\hline & Good & 120 & 52.17 \\
\hline & Average & 45 & 19.57 \\
\hline & Bad & 5 & 2.17 \\
\hline \multirow{4}{*}{ Availability of paramedical and technical personnel } & Very satisfactory & 71 & 30.87 \\
\hline & Satisfactory & 122 & 53.04 \\
\hline & Less satisfactory & 32 & 13.91 \\
\hline & Unsatisfactory & 5 & 2.17 \\
\hline \multirow{4}{*}{ Paramedical and technical care quality } & Excellent & 62 & 26.96 \\
\hline & Good & 116 & 50.43 \\
\hline & Average & 50 & 21.74 \\
\hline & $\mathrm{Bad}$ & 2 & 0.87 \\
\hline \multirow{3}{*}{ Intense of pain $(n=108)$} & More intense pain & 37 & 34.25 \\
\hline & Intense pain & 40 & 37 \\
\hline & Less strong & 31 & 28.7 \\
\hline \multirow{3}{*}{ Pain's care delay $(n=108)$} & Without any delay & 34 & 31.48 \\
\hline & Long & 53 & 49.10 \\
\hline & Very long & 21 & 19.42 \\
\hline \multirow{4}{*}{ Pain's care $(n=108)$} & Very satisfactory & 15 & 13.90 \\
\hline & Satisfactory & 59 & 54.63 \\
\hline & Insufficient & 22 & 20.37 \\
\hline & Very bad & 12 & 11.10 \\
\hline \multirow{4}{*}{$\begin{array}{l}\text { The care offered in case of pathology's parallel } \\
\text { discomforts (nausea, vomiting, and bad position...) } \\
(n=79)\end{array}$} & Very satisfactory & 16 & 20.25 \\
\hline & Satisfactory & 32 & 40.51 \\
\hline & Insufficient & 17 & 21.52 \\
\hline & Very bad & 14 & 17.72 \\
\hline
\end{tabular}

It should be remembered that the Oncology Hospital of the Hassan II University Hospital is a new establishment that started in 2012, with high performance equipment and support of "Foundation Lalla Salma against cancer". This can partially explain these results. Nevertheless, this satisfaction data should be cautiously interpreted since the study is conducted in one department of oncology hospital whish contains two other departments.

Concerning orientation in the institution, the results were less satisfactory $(66.81 \%)$. Similarly, nearly half of the surveyed patients (44.34\%) judged administrative procedures as complicated or very complicated. These results are similar to those reported in the first satisfaction survey conducted on cancer patients at Hassan II University Hospital [12]. This is attributed to the socio-demographic characteristics of the surveyed population, particularly educational level, where $52.61 \%$ are illiterate and $23.48 \%$ have primary level. However, reception and orientation must be developped and considerable efforts must be made to simplify the administrative formalities.

At the Radiotherapy department, the cost of medication was judged as too expensive by only $2.61 \%$ of patients, whereas others expressed their unconcern. This is because (92.61\%) of patients had a low socio-economic level and a social health insurance [29] which guarantees free medical care.

The low satisfaction concerned also the appointments given by Radiotherapy department (60.44\%) and the waiting time which was considered very long either at the level of the Radiotherapy department $(42.58 \%)$ or at admission office (40\%). However, waiting conditions were generally comfortable in $67.25 \%$ cases at the Radiotherapy department and $61.30 \%$ at the admission office. Several authors have found that waiting time is a very important factor of dissatisfaction $[30,31]$. Other studies $[32,33]$, on the other hand, have shown that patient satisfaction does not seem to depend on the actual concept of waiting, as long as it corresponds to trust caregivers and perception of time. These delays can also be justified by the absence of a precise pre-appointment in the Radiotherapy department. Cancer patients come without a prior appointment; this makes waiting duration longer. In addition, most cancer cases were cured at the department requiring radiotherapy for several medication sessions. Patients should be informed about medication procedures and estimated waiting time as soon as they arrived to the department in order to avoid confusion inadequacies. Patients' average satisfaction with appointments can be 
TABLE 6: Cancer patient satisfaction with human aspects (Hassan II CHU, Fez, 2017).

\begin{tabular}{lccc}
\hline & & Number & $\%$ \\
\hline & Excellent & 126 & 54.78 \\
Doctors' behaviour & Good & 81 & 35.22 \\
& Average & 21 & 9.13 \\
& Bad & 2 & 0.87 \\
& Excellent & 99 & 43.23 \\
Nurses' behaviour & Good & 90 & 39.30 \\
& Average & 35 & 15.28 \\
& Bad & 5 & 2.18 \\
Physicians' and technicians' & Excellent & 93 & 40.61 \\
behaviour & Good & 85 & 37.12 \\
& Average & 27 & 11.79 \\
& Bad & 24 & 10.14 \\
Did you feel that you were & Absolutely & 113 & 49.13 \\
respectably treated? & Yes & 80 & 34.78 \\
& No & 31 & 13.48 \\
& Never & 6 & 2.61 \\
& Absolutely & 117 & 50.87 \\
Was your intimacy respected? & Yes & 80 & 34.78 \\
& No & 21 & 9.13 \\
& Never & 8 & 3.48 \\
\hline
\end{tabular}

influenced by patients' confusion between the appointments destined for biological or radiological control at Hassan II University Hospital and those concerned radiotherapy's cure procedure inside the department, knowing that this latter is done without prior schedule.

Other aspects specific to cancer patients concern the pain management, discomfort related to disease (nausea, vomiting, etc.) and psychological features. In general, the management of pain was appreciated by patients $(68.5 \%)$. This rate is relatively lower than that found by the first conducted survey at Hassan II University Hospital on cancer patients (77.3\%) [12]. However Similar results found in public hospitals in Casablanca (69.2\%) [13]. This pain management has become an integral part in care process in Morocco.

The results of discomforts' cure related to disease were relatively satisfactory $(60.75 \%)$ but inferior to those of the first study carried out at Hassan II University Hospital on cancer patients (80.64\%) [12].

For the cure of psychological anxiety, the majority of the patients declare not having benefited from psychotherapy. The Oncology Hospital of Hassan II University Hospital has recently set up a palliative care unit that will further focus on the psychological management, pain and all the discomforts related to this heavy pathology in order to improve the quality of care for cancer patients.

The results about disease explanation, including advice on the rules to follow for a better lifestyle were slightly satisfactory. Special attention should be given to this aspect: a better communication and information of the patient on his health problems, the medication to be under taken, the examinations to be carried out, the diet to be followed and the hygienic measures in general.
Another crucial parameter was studied. It corresponded to human aspect, including the behavior and support of caregivers' staff, respect of intimacy and the sensation of being respectably cured. The results obtained were excellent or good in the majority of cases, which is comparable to those found in other Moroccan studies [12, 13]. However, they remain lower than those found in several foreign studies $[25,28,34]$.

The results show very high satisfaction rates for patients cured at Radiotherapy department. One explanation for these results is that competence of health-care team, the sophisticated technical platform and the benevolence of managers to put a quality assurance system which played an important role in boosting satisfaction rates. Nevertheless, efforts are necessaryto improve the quality of certain services provided in order to better satisfy these cancer patients. Improvement should concentrate on:

(i) Improving the pain management through training of health professionals and introducing other methods of pain medications.

(ii) Improving patients' reception conditions and comfort in waiting rooms at the Radiotherapy department.

(iii) Humanizing the practices of health care professionals: respecting patients' intimacy and empathy.

(iv) Building effective communication between members of the health care team, patients, and their relatives.

(v) Eliciting skilful volunteers who can assist patients in administrative procedures.

(vi) Simplification of administrative procedures and organization of patients' circuit inside the department and in the hospital.

(vii) Promote the newly created palliative care unit in the Radiotherapy department and introduce psychological care for cancer patients.

\section{Conclusion}

This sample offered primary results to attain the objectives of the study. However, it should be extended to include the two departments of Oncology Hospital and with a wider patients' sampling to guarantee a complete study. Furthermore, quality approach and establishment project, which aim strengthening the hospital's position as a care-leading hospital center, were adopted by Hassan II University Hospital. We recommend the consideration of this survey in other hospital department for the ultimate goal of improving patients' care quality.

\section{Data Availability}

The data used and analyzed during the current study are available from the corresponding author on reasonable request.

\section{Conflicts of Interest}

The authors declare that they have no conflict of interest. 


\section{Funding}

This research did not receive any specific grant from funding agencies in the public, commercial, or not-for-profit sectors.

\section{Acknowledgments}

The authors would like to thank all patients who participated.

\section{References}

[1] P. D. Cleary and B. J. Mc Neil, "Patient satisfaction as an indicator of quality of care," Inquiry, vol. 25, no. 1, pp. 25-36, 1988.

[2] A. Donabedian, "The quality of care. How can it beassessed?" Journal of the American Medical Association, vol. 260, no. 12, pp. 1743-1748, 1988.

[3] J. Labarère and P. François, "Évaluation de la satisfaction des patients par les établissements de soins," Revue de la Littérature. Rev Épidemiol Santé Publique, vol. 47, no. 2, pp. 175-184, 1999.

[4] F. Barlési, L. Chabert-Greillier, A. Loundou et al., "Validation de la version française du princess margaret hospital patient satisfaction with doctor questionnaire (PMH/PSQ-MD): le F-PMH/PSQ MD," Revue des Maladies Respiratoires, vol. 23, no. 4, pp. 227-236, 2006.

[5] Inspection Générale des Affaires Sociales, La mesure de la satisfaction des usagers des établissements de santé, IGAS, Paris, 2007.

[6] A. Vanninneuse, "La satisfaction du patient en orthopédietraumatologie," E-Mém Académie NatlChir, vol. 3, no. 4, pp. 9-13, 2004.

[7] Ordonnance $\mathrm{n}^{\circ}$ 96-346 du 24 avril 1996 art 1er, art. L. 710-1-1 code de la sante publique, Paris : Dalloz, 12e edition, 1997.

[8] R. Poinsot, A. Altmeyer, T. Conroy et al., "Validation multicentrique d'un questionnaire de satisfaction des soins lors d'un traitement de chimiothérapie ou radiothérapie ambulatoire," Bulletin du Cancer, vol. 93, no. 3, pp. 315-327, 2006.

[9] J. H. Wiggers, K. O. Donovan, S. Redman, and R. W. SansonFisher, "Cancer patient satisfaction with care," Cancer, vol. 66, no. 3, pp. 610-616, 1990.

[10] Registre des cancers de la Région du Grand Casablanca (RCRGC), 2008-2012, https://www.contrelecancer.ma/fr/ documents/registre-des-cancers-de-la-region-du-grandcasab-3/

[11] "Registre Hospitalier des Cancers du Centre HospitaloUniversitaire Hassan II (CHU Hassan II)," 2017, Rapport.

[12] K. Amazian, I. Toughrai, N. Benmansour, S. Ait Laalim, M. El Amine El Alami, and K. Mazaz, "Enquête de satisfaction des patients atteints de cancer dans un hôpital universitaire au Maroc," Santé Publique, vol. 5, no. 25, pp. 627-632, 2013.

[13] S. Nani, S. Hassoune, F. Ihbibane, I. Imdary, M. Toumlilt, and H. Guejimi, "Évaluation de la satisfaction des patients dans les hôpitaux publics de Casablanca, Maroc," Médecine du Maghreb, vol. 200, pp. 37-47, 2012.

[14] F. Z. Arfaoui, S. Karkouri, N. Bennis, A. A. Eloumri, and N. Hajjaj-Hassouni, "Enquête sur la satisfaction des patients porteurs d'orthèse cruropédieuse réalisée au sein d'atelier d'appareillage de l'hôpitalEl-Ayachi," Annals of Physical and Rehabilitation Medicine, vol. 54, pp. e2-e10, 2011.
[15] N. Damghi, J. Belayachi, B. Armel et al., "Patient satisfaction in a Moroccan emergency department," International Archives of Medicine, vol. 6, no. 1, p. 20, 2013.

[16] J. Kasouati, L. Bouti, O. Zidouh, Z. Abd El Hamid, A. Boufaresse, and M. Mrabet, "Évaluation de la satisfaction des patients de la prise en charge de la douleur au service des urgences de l'Hôpital Militaire d'Instruction Mohamed V, Rabat, Maroc,' Revue d'Épidémiologie et de Santé Publique, vol. 63, p. S75, 2015.

[17] A. Mtiraoui and B. Alouini, "Evaluation de la satisfaction des patients hospitalisés à l'hôpital de Kairouan," La Tunisie Medicale, vol. 80, pp. 113-121, 2002.

[18] N. Midoun, N. Boumansour, A. A. Dali et al., "Mesure de la satisfaction des patients hospitalisés dans un établissement hospitalier universitaire, vis-à-vis de la qualité des soins, de la restauration et de la relation avec le personnel," Revue d'Epidémiologie et de Santé Publique, vol. 64, no. S4, p. 243, 2016.

[19] R. A. F. Kabore, K. Tomta, K. B. Ki et al., "Evaluation de la satisfaction des patients d'un service d'urgences," Journal de la Recherche Scientifique de l'Université de Lomé, vol. 15, no. 3, 2013.

[20] A. R. Yameogo, G. R. C. Millogo, A. F. Palm et al., "Évaluation de la satisfaction des patients dans le service de cardiologie du CHU Yalgado Ouedraogo," Pan African Medical Journal, vol. 28, p. 267, 2017.

[21] I. Bougmiza, M. EL Ghardallou, C. Zedini et al., "Evaluation de la satisfaction des patientes hospitalisées au service de gynécologie obstétrique de Sousse," Tunisie Pan African Medical Journal, vol. 8, no. 1, p. 44, 2011.

[22] M. Letaief, A. Bchir, K. Bensalem, and M. S. Soltani, "Evaluation de la satisfaction des patients dans un hôpital universitaire en Tunisie," Journal of Medical Economics, vol. 19, no. 7-8, pp. 527-32, 2001.

[23] B. Moifo, E. GuegangGoujou, O. F. Zeh, Melong V. Thimnoue, and Manka'a Wankie M. Nguemgne, C., K. J. Gonsu and P. E. Belley, "Enquête de satisfaction des patients au service de radiologie de l'hôpital général de douala-Cameroun," Journal of African mag Méd, vol. 1, no. 6, pp. 52-63, 2014.

[24] A. Brédart, C. Coens, N. Aaronson et al., Bottomley, "Determinants of patient satisfaction in oncology settings from European and Asian countries: preliminary results based on the EORTC IN-PATSAT32 questionnaire," European Journal of Cancer, vol. 43, no. 2, pp. 323-330, 2007.

[25] C. Fabry, "Les questionnaires de sortie aux HCL, expression de lécoute des patients," Journal des Hospices civils de Lyon, vol. 107, pp. 28-29, 2003.

[26] I. Gasquet, S. Villeminot, C. Estaquio, P. Durieux, P. Ravaud, and B. Falissard, "Construction of a questionnaire measuring out patients' opinion of quality of hospital consultation departments," Health and Quality of Life Outcomes, vol. 2, p. 43, 2004.

[27] S. Tat and D. Barr, "Healthcare in the New Vietnam: comparing patients' satisfaction with out patient care in a traditional neighborhood clinic and a new, western-style clinic in Ho Chi Minh City," Social Science \& Medicine, vol. 62, no. 5, pp. 1229-1236, 2006.

[28] Z. Muraj, M. Kwan, M. Wake, K. Tse, and L.-A. Swanson, "Assessing patient satisfaction in a radiation therapy department using a survey tool," Journal of Medical Imaging and Radiation Sciences, vol. 46, no. 2, pp. 182-188, 2015.

[29] Decret $\mathrm{n}^{\circ} 2-08-177$ du 28 ramadan 1429 (29 septembre 2008) portant application des dispositions du livre III de la loi $\mathrm{n}^{\circ}$ 
65-00relatives au régime d'assistance médicale tel qu'il a été modifié et complété par le décret $\mathrm{n}^{\circ}$ 2-11-199 du 07 chaoual 1432, 2011, http://www.ramed.ma.

[30] L. Hanberger, J. Ludvigsson, and S. Nordfeldt, "Quality of care from the patient's perspective in pediatric diabetes care," Diabetes Research and Clinical Practice, vol. 72, no. 2, pp. 197-205, 2006.

[31] N. Daqdeviren and Z. Akturk, "An evaluation of patient satisfaction in Turkey with the EUROPEP instrument," Yonsei Medical Journal, vol. 45, no. 1, pp. 23-28, 2004.

[32] E. Boudreaux and E. O'Hea, "Patient satisfaction in the emergency Department: are view of the literature and implications for practice," The Journal of Emergency Medicine, vol. 26, no. 1, pp. 13-26, 2004.

[33] J. Hedges, A. Trout, and A. Magnusson, "Satisfied patients exiting the emergency department (SPEED) study," Academic Emergency Medicine, vol. 9, no. 1, pp. 15-21, 2002.

[34] A. Charalambous, "Variations in patient satisfaction with care for breast, lung, head and neck and prostate cancers in different cancer care settings," European Journal of Oncology Nursing, vol. 17 , no. 5, pp. 588-595, 2013. 


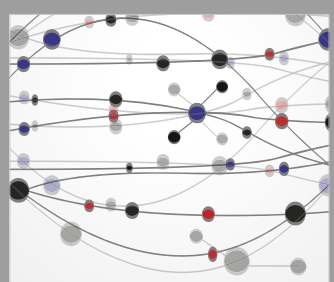

The Scientific World Journal
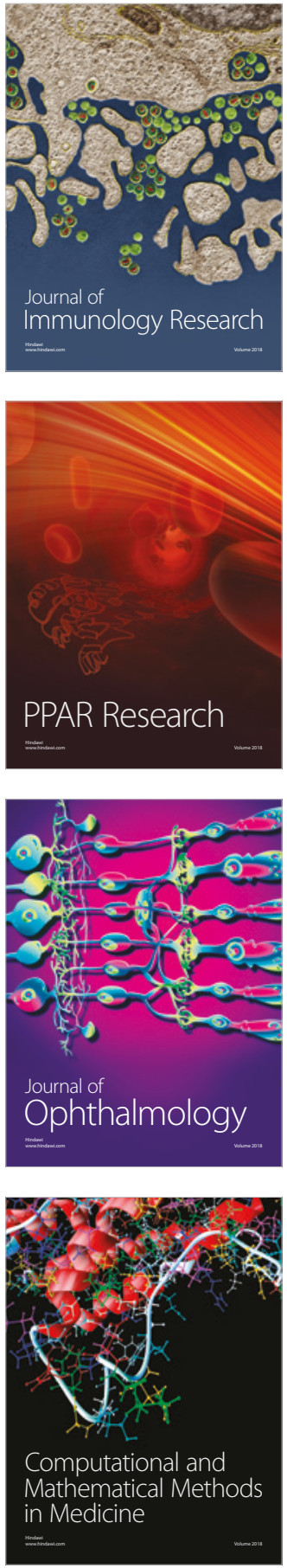

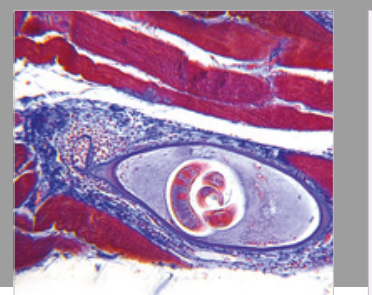

Gastroenterology Research and Practice

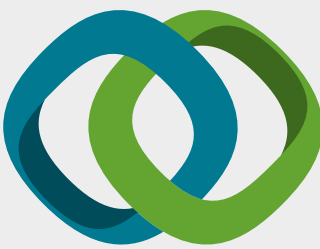

\section{Hindawi}

Submit your manuscripts at

www.hindawi.com
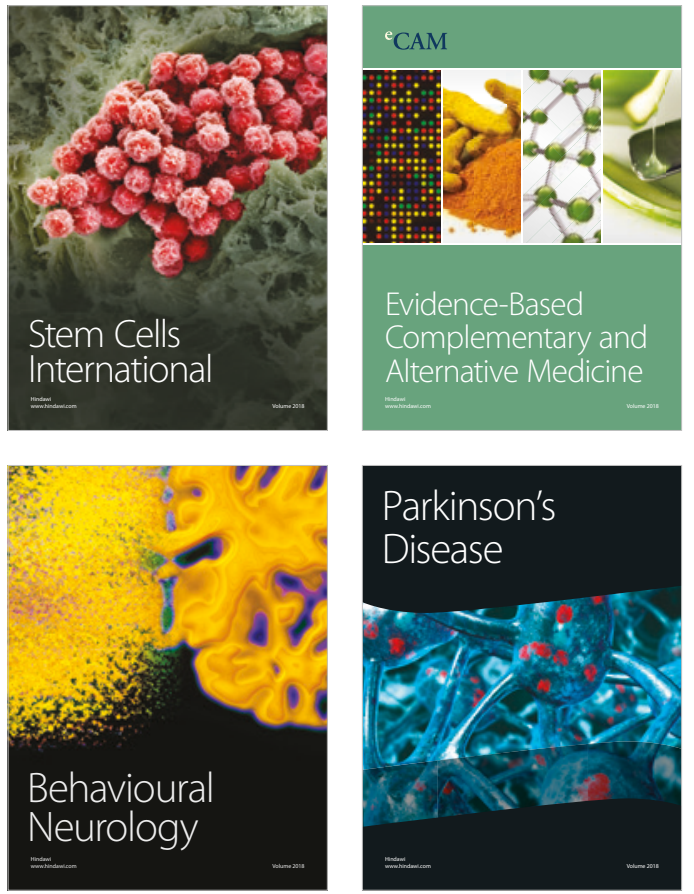

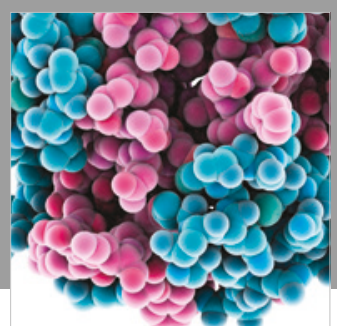

ournal of

Diabetes Research

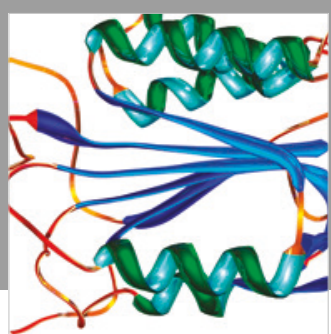

Disease Markers
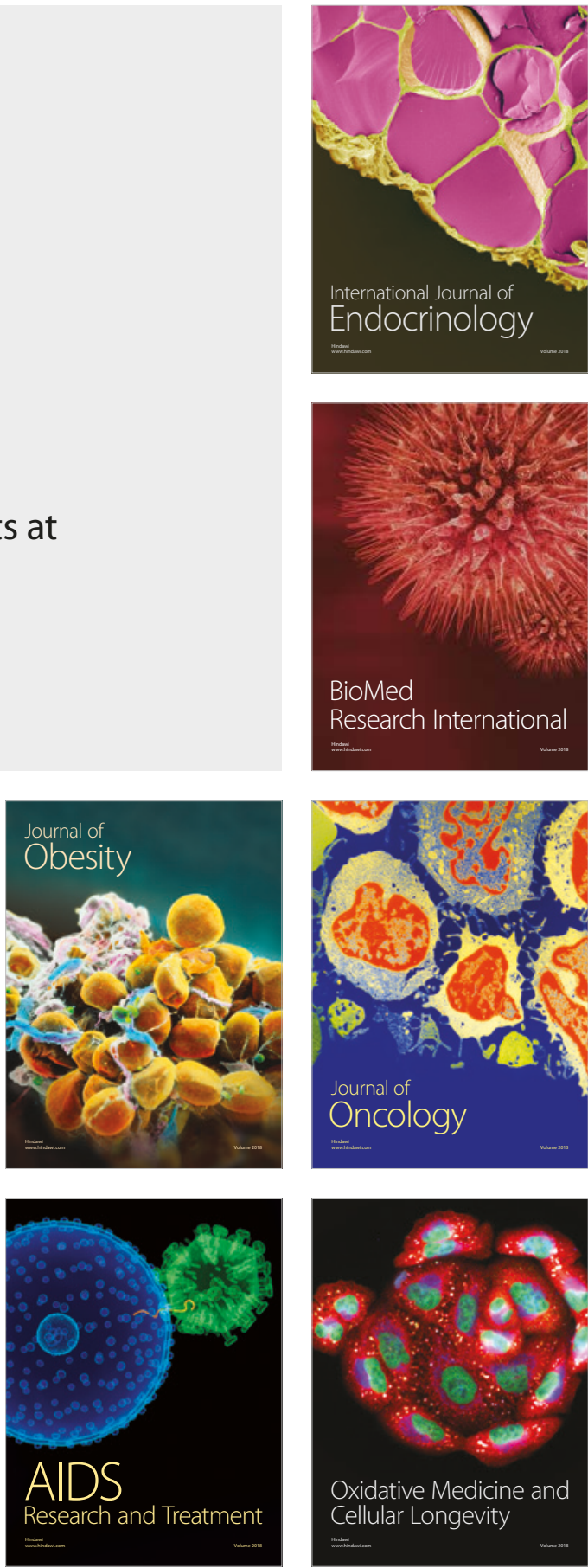